\title{
Copper-catalyzed stereo- and chemoselective synthesis of enaminones via Michael type addition
}

\author{
MONIKA PATEL, SUSHMITA and AKHILESH KUMAR VERMA* \\ Synthetic Organic Chemistry Research Laboratory, Department of Chemistry, University of Delhi, \\ Delhi 110 007, India \\ E-mail: averma@acbr.du.ac.in
}

MS received 5 March 2018; revised 12 April 2018; accepted 16 April 2018; published online 14 June 2018

\begin{abstract}
An efficient strategy for the synthesis of $\alpha, \beta$-unsaturated enaminones by the nucleophilic addition of $N$-heterocycles such as indole and imidazoles onto electronically bias alkynones under mild reaction conditions is described. Key feature of this reaction is the chemoselective addition of $N$-heterocycles onto ynones without affecting the $1^{\circ}$ amino groups (aromatic and aliphatic) of 5-aminoindole and tryptamine. The stereochemistry of the products was controlled by the tuning of reaction time. The mechanism of the reaction involves the Michael type addition of $N$-heterocycles on ynones via allene formation.
\end{abstract}

Keywords. Copper; alkynones; hydroamination; Michael addition; enaminones.

\section{Introduction}

For more than a century, 1,3-dicarbonyl compounds and their derivatives have been one of the most versatile and frequently employed C-3 synthons in organic synthesis. ${ }^{1}$ Among them, enaminones ${ }^{2}$ have been used in synthetic chemistry since a long time. One reason for their widespread application is their versatile reactivity, both as electrophiles and nucleophiles. Enaminones are the vinylogous amides that are resonance-stabilized and known to have high nucleophilicity. They are the enamines of carbonyl compound resembling chalcones and are well known for their intrinsic pharmacological and biological properties. ${ }^{3}$ Many reports on the antioxidants, antiproliferative, antibacterial, anticancer, cytotoxic agents and chemopreventive properties of enaminones have been discussed in the literature. ${ }^{4}$

Enaminones occupy an important place as intermediates in target oriented organic synthesis. ${ }^{5}$ They are considered as vital synthetic targets because of the subsequent reactivity of their double bond, often working as substrates for addition or redox reaction. Enamine and imines both function as reagents for the introduction of $N$-containing moieties into a synthetic sequence. The $\pi$ electron delocalization and presence of $\alpha, \beta$-unsaturated

\footnotetext{
*For correspondence
}

bond are the two specific characteristic of enaminones which makes them reactive. Due to their significant utility in organic synthesis, a number of methods have been developed for the preparation of enaminones. ${ }^{6,7}$ For decades, enaminones were prepared by the general reaction of amines and 1,3-diketones which are established substrates in heterocyclic chemistry. ${ }^{8}$ However; the conventional methodology suffers from various drawbacks. The utilization of ynones is a common strategy in the synthesis of many biologically important compounds. ${ }^{9}$

In 2003, Muller and co-workers ${ }^{5 \mathrm{~b}}$ described Sonogashira coupling of acid chloride followed by addition of non-heterocyclic amines on to alkynone (Scheme 1a). Later, Jiang group ${ }^{10}$ reported the multicomponent domino synthesis of tetrahydropyridine using L-proline as a catalyst (Scheme 1b). Subsequently, Chauhan and researchers ${ }^{11}$ reported the two-step synthesis of chalcones derivatives via reaction of indolyl acetophenone with carbonyl substrate (Scheme 1c). In 2012, Trofimov and co-workers ${ }^{12}$ demonstrated the superbase promoted $\alpha$-vinylation of aliphatic, alicyclic, and alkyl aromatic ketones with arylacetylenes for the synthesis of $\beta, \gamma$ unsaturated ketones (Scheme 1d). In reference to the above approaches and ongoing research of our group on hydroamination chemistry, ${ }^{13,14}$ herein we report coppercatalyzed nucleophilic addition of $N$-heterocycles onto 
Previous Work

a) Muller and co-workers, 2003

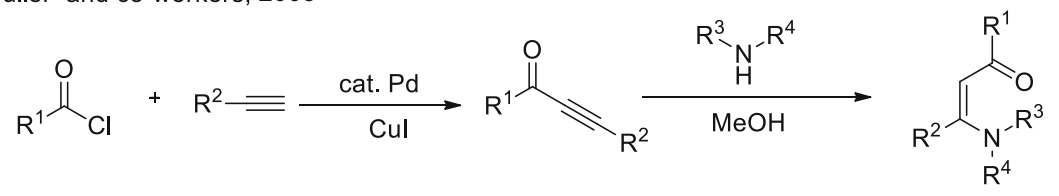

b) Jiang and co-workers, 2010<smiles>[R]C#CC([R])=O</smiles>

c) Chauhan and co-worker, 2011<smiles>c1ccc2[nH]ccc2c1</smiles><smiles>O=C(NOc1ccccc1)C(=O)Nc1ccc2ccn(CC(=O)c3ccccc3)c2c1</smiles>

d) Trofimov and co-workers, 2012<smiles>[R]CC([R])=O</smiles>

Present Work

e)

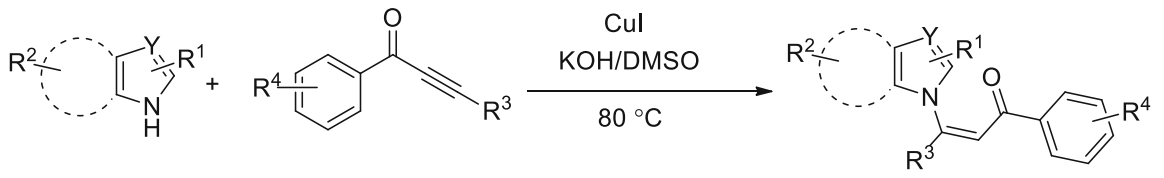

Scheme 1. Previous strategies vs. present work.

alkynones to synthesize $\alpha, \beta$-unsaturated enaminones (Scheme 1e).

\section{Experimental}

\subsection{Material and physical measurements}

The chemicals and reagents used for the synthesis were obtained from commercial sources. Solvents were distilled from an appropriate drying agent. Heterocycles, benzoyl chloride and alkynes (Sigma Aldrich) were used as received. All other chemicals and solvents were of analytical grade. All the reactions were performed in an oven-dried Schlenk flask under an argon atmosphere. Column chromatography was performed using neutral and basic alumina. TLC analysis was performed on commercially prepared $60 \mathrm{~F}_{254}$ silica gel plates. Visualization of spots on TLC plate was accomplished with UV light $(254 \mathrm{~nm})$ and staining over the $\mathrm{I}_{2}$ chamber. ${ }^{1} \mathrm{H}$ NMR $(400 \mathrm{MHz})$ and ${ }^{13} \mathrm{C}$ NMR $(100 \mathrm{MHz})$ spectra were recorded in $\mathrm{CDCl}_{3}$ and DMSO-d $\mathrm{d}_{6}$. Chemical shifts for carbons are reported in ppm from tetramethylsilane and are referenced to the carbon resonance of the solvent. Data are reported as follows: chemical shift, multiplicity $(\mathrm{s}=$ singlet, $\mathrm{d}=$ doublet, $\mathrm{t}=$ triplet, $\mathrm{q}=$ quartet, $\mathrm{m}=$ multiplet, $\mathrm{dd}=$ doublet of doublet, br s = broad), coupling constants in Hertz, and integration. High-resolution mass spectra were recorded with q-TOF electrospray mass spectrometer, and Infrared spectra were recorded on an FT-IR spectrophotometer.

\subsection{Synthesis of alkynone $\mathbf{2}$}

The alkynone $\mathbf{2}$ was prepared by the Sonogashira coupling reaction of corresponding benzoyl chloride with terminal alkynes. To a solution of $\mathrm{Pd}\left(\mathrm{PPh}_{3}\right)_{2} \mathrm{Cl}_{2}(2 \mathrm{~mol} \%)$ and $\mathrm{CuI}$ (4 mol\%) in THF under an inert atmosphere, alkyne $(0.5$ $\mathrm{mmol})$, benzoyl chloride $(0.5 \mathrm{mmol})$ and base triethyl amine $(0.5 \mathrm{mmol})$ were added. Resulting mixture was stirred at $25^{\circ} \mathrm{C}$ (room temperature) for $30-45 \mathrm{~min}$. The progress of the reaction was monitored by TLC. After the complete consumption of the starting substrate, the reaction mixture was extracted with ethylacetate $(5 \mathrm{~mL} \times 3)$ and evaporated under reduced pressure. The crude reaction mixture was purified using silica gel column chromatography (EtOAc: Hexane ::5: 95). 


\subsection{Synthesis of enaminones $\mathbf{3}$}

To a solution of $N$-heterocycle $1(0.5 \mathrm{mmol})$ in DMSO and finely crushed $\mathrm{KOH}(0.2$ equiv. $)$, alkynone $2(0.3 \mathrm{mmol})$ and $\mathrm{CuI}(2 \mathrm{~mol} \%)$ was added. Resulting mixture was heated at $80^{\circ} \mathrm{C}$ for $10-15 \mathrm{~min}$. Progress of the reaction was monitored by TLC. After the complete consumption of the starting substrate, reaction mixture was brought to room temperature. The reaction mixture was extracted with ethylacetate $(5 \mathrm{~mL} \times 3)$ and evaporated under reduced pressure. The crude reaction mixture was purified using silica gel column chromatography.

\subsection{Characterization of alkynone $\mathbf{2 a}$}

1-(3-(Trifluoromethyl)phenyl)-3-(trimethylsilyl)prop-2-y n-1-one. The product was obtained as a pale white oil (117.4 $\mathrm{mg}, 87 \%$ ); ${ }^{1} \mathrm{H}$ NMR (400 MHz, $\mathrm{CDCl}_{3}$ ) $\delta 8.38$ (s, 1H), 8.30 $(\mathrm{d}, J=7.3 \mathrm{~Hz}, 1 \mathrm{H}), 7.84(\mathrm{~d}, J=9.5 \mathrm{~Hz}, 1 \mathrm{H}), 7.65-7.60$ $(\mathrm{m}, 1 \mathrm{H}), 0.32(\mathrm{~s}, 9 \mathrm{H}) ;{ }^{13} \mathrm{C} \mathrm{NMR}\left(100 \mathrm{MHz}, \mathrm{CDCl}_{3}\right) \delta 176.1$, $136.9,132.6,130.4,129.3,126.3$ (q, $J=3.8 \mathrm{~Hz}, 1 \mathrm{C}$ ), 102.4, 100.1, -0.8. HRMS (EI) $[\mathrm{M}]^{+}$Calcd. for $\left[\mathrm{C}_{13} \mathrm{H}_{13} \mathrm{~F}_{3} \mathrm{OSi}\right]$ 270.0688 , found 270.0688 .

\subsection{Characterization of compound 3a}

(Z)-3-(1H-Indol-1-yl)-1-(3-(trifluoromethyl)phenyl)prop -2-en-1-one

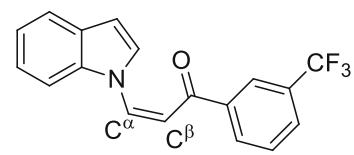

Compound 3a was prepared by the addition of 0.2 equiv. of $\mathrm{KOH}$ and $\mathrm{CuI}(2 \mathrm{~mol} \%)$ in the solution of indole 1a and 1-(3-(trifluoromethyl)phenyl)-3-(trimethylsilyl)prop2-yn-1-one 2a in DMSO. The reaction mixture was heated at $80^{\circ} \mathrm{C}$ for $15 \mathrm{~min}$. The structure of compound 3a was established on the basis of its spectral data analysis. Its high-resolution mass spectrum showed $[\mathrm{M}]^{+}$peak at $\mathrm{m} / \mathrm{z}$ 315.0871, which confirmed its molecular formula to be $\mathrm{C}_{18} \mathrm{H}_{12} \mathrm{~F}_{3} \mathrm{NO}$. In the ${ }^{1} \mathrm{H}$ NMR spectrum in $\mathrm{CDCl}_{3}$ at $400 \mathrm{MHz}$, the characteristic peaks of the styryl protons at $\mathrm{C}^{\alpha}$ and $\mathrm{C}^{\beta}$ appeared at $\delta 8.14$ and $7.74 \mathrm{ppm}$ with a coupling constant $J$ of 7.7 and $7.8 \mathrm{~Hz}$, respectively, suggesting the formed isomer as a $Z$-isomer. Similarly, the ${ }^{13} \mathrm{C} N M R$ spectrum in $\mathrm{CDCl}_{3}$ at $100 \mathrm{MHz}$, appearance of the quartet carbon at $\delta 125.1 \mathrm{ppm}$ shows the formation of an addition product. The peaks of all other protons and carbons of the molecule were present in ${ }^{1} \mathrm{H}$ and ${ }^{13} \mathrm{C}$ NMR spectra of the molecule in Supplementary Information.

\section{Results and Discussion}

\subsection{Optimization of the reaction condition}

To identify the optimal reaction conditions, we have screened various bases and solvents under certain interval of time at different temperatures. We began our investigation using indole 1a and 1-(3-(trifluoromethyl) phenyl)-3-(trimethylsilyl)prop-2-yn-1-one $\mathbf{2 a}$ as our model substrates (Table 1).

Inspired by our previous conditions for hydroamination, we performed the reaction of $\mathbf{1 a}$ with $\mathbf{2 a}$ in the presence of 0.2 equiv. of $\mathrm{KOH}$ in $\mathrm{DMSO}$ at $120^{\circ} \mathrm{C}$ for 30 min yielded $24 \%$ of the $E$-isomer $3 \mathbf{a}$ (Table 1, entry 1). Decreasing the reaction temperature from $100^{\circ} \mathrm{C}$ to $80{ }^{\circ} \mathrm{C}$ provided the desired product 3a in $44 \%$ and $54 \%$ yield, respectively (entries 2 and 3 ). Lowering the reaction time from $30 \mathrm{~min}$ to $20 \mathrm{~min}$ leads to a mixture of $E$ and $Z$ stereoisomers (entry 4 ). On tuning the reaction time to $15 \mathrm{~min}$, the $Z$-isomer $\mathbf{3 a}$ was obtained in $59 \%$ yield (entry 5 ). Further lowering the reaction time leads to the incompletion of the reaction (entries 6 and 7). Enhancing the amount of $\mathrm{KOH}$ to 0.5 equiv. did not make any significant effect on the yield of the reaction (entry 8). Interestingly, the addition of $2 \mathrm{~mol} \%$ of $\mathrm{CuI}$ improved the yield of hydroaminated product $3 \mathbf{a}$ to $74 \%$ (entry 9). However, no significant change in the yield of the product was observed when $5 \mathrm{~mol} \%$ of $\mathrm{CuI}$ was used (entry 10). Other inorganic bases such as $\mathrm{NaOH}$, $\mathrm{CsOH} \cdot \mathrm{H}_{2} \mathrm{O}$, and $\mathrm{K}^{+} \mathrm{O}^{t} \mathrm{Bu}$ were found to be ineffective for the reaction (entries 11-13). Inferior results were obtained when $\mathrm{Et}_{3} \mathrm{~N}$ was used as a base (entry 14). Next, we screened the solvents for the designed reaction and to our interest moderate yield was obtained with NMP, though other solvents like toluene, DMF and MeCN failed to give the desired product (entries 15-18).

\subsection{Hydroamination of alkynones with $\mathrm{N}$-heterocycles}

Our preliminary investigation revealed that the optimal reaction condition for the synthesis of diversely substituted styryl enaminones was $2 \mathrm{~mol} \%$ of $\mathrm{CuI}$ and 0.2 equiv. $\mathrm{KOH}$ in $\mathrm{DMSO}$ at $80^{\circ} \mathrm{C}$ for $15 \mathrm{~min}$. Addition of $N$-heterocycles $1 \mathbf{a}-\mathbf{h}$ on alkynones $\mathbf{2 a}-\mathbf{f}$ provided the corresponding hydroaminated products $\mathbf{3 a}-\mathbf{u}$ in moderate to good yields (Table 2, entries 1-21). It was noticed that the nature of the heteroarenes and the substituents attached to the triple bond has a major impact on the success of the process. It was motivating to find that reaction of heterocycles $1 \mathbf{a}$ with electronwithdrawing alkynone 1-(3-(trifluoromethyl)phenyl)-3(trimethylsilyl)prop-2-yn-1-one 2a provided Z-isomer 3a as major product with the hydrolysis of TMS within $15 \mathrm{~min}$ in $74 \%$ yield (entry 1). High temperature and longer reaction time led to the decomposition of product. Intermolecular addition of indole 1a on to internal alkynone $\mathbf{2 b}-\mathbf{d}$ provided the hydroaminated products $\mathbf{3 b}-\mathbf{d}$ in $70 \%$, 72\% and $70 \%$ yields, respectively 
Table 1. Optimization of the reaction conditions. ${ }^{\text {a }}$

\begin{tabular}{lccccc} 
1a & & & & \\
\hline
\end{tabular}

${ }^{\text {a }}$ Reactions were performed using $N$-heterocycle $1 \mathbf{a}(0.5 \mathrm{mmol})$, alkyne $\mathbf{2 a}(0.3$ $\mathrm{mmol}$ ) in $2.0 \mathrm{~mL}$ of solvent under nitrogen atmosphere. ${ }^{\mathrm{b}}$ Total yield of two isomers. ${ }^{\mathrm{c}}$ Sterioisomeric ratio. ${ }^{\mathrm{d}} \mathrm{CuI}(2 \mathrm{~mol} \%) .{ }^{\mathrm{e}} \mathrm{CuI}(5 \mathrm{~mol} \%)$.

(entries 2-4). Electron-rich amines like 3-methylindole $\mathbf{1 b}$ reacted smoothly with alkynones $\mathbf{2 b}-\mathbf{d}$ and providing the desired products $\mathbf{3} \mathbf{e}-\mathbf{g}$ in good yields (entries 5-7). Interestingly, chemoselective hydroamination was obtained when tryptamine 1c and 5-aminoindole 1d were used as substrates without affecting the primary amine group (entries 8-15). The 5-methoxyindole 1e and 5-bromoindole 1f were compatible under our screened conditions and afforded the Z-styryl alkynones 3p-r in 63-59\% yield (entries 16-18). The NOE studies of the enaminone $\mathbf{3 p}$ confirm the orientation of the rings in the product. Subtle switching from indole nucleus to imidazole moiety $\mathbf{1 g}$ successfully gave the addition product $3 \mathrm{~s}$ in $67 \%$ yield (entry 19 ). Similarly, the reaction of sterically hindered heterocycle $\mathbf{1 h}$ with 1-(2-bromophenyl)-3-( $p$-tolyl)prop-2-yn-1-one $\mathbf{2 b}$ and 3-(m-tolyl)-1-(3-(trifluoromethyl) phenyl)prop-2-yn-1one $2 \mathbf{f}$ afforded the styrylenaminones $3 \mathbf{t}$ and $\mathbf{3 u}$ in 61 and $60 \%$ yield respectively (entries 20 and 21 ). However, the alkyl ynone $\mathbf{2 g}$ failed to provide the hydroaminated product $\mathbf{3 v}$ instead an inseparable complex mixture was obtained (entry 22).

\subsection{Plausible mechanism}

The addition of $N$-heterocycle $\mathbf{1}$ to the corresponding alkynone $\mathbf{2}$ takes place in accordance with Michael addition reaction (Scheme 2). The hydroxide generates a nucleophile $\mathbf{P}$ that attacks the electrophilic alkyne conjugated with the carbonyl group giving rise to an allene $\mathbf{Q}$ via polarization of $\mathrm{Cu}$. Species $\mathrm{Q}$ rearranges into species $\mathbf{R}$ which undergoes protometal leading to the formation of enaminone $\mathbf{3}$.

\section{Conclusions}

We have developed an efficient and simple strategy for the synthesis of $\alpha, \beta$-unsaturated enaminones by the nucleophilic addition of $N$-heterocycles onto alkynones under mild reaction conditions. The addition of catalytic amount of copper facilitates the attack of nucleophile onto alkynones. The developed protocol provides regio-, stereo- and chemoselective syntheses of $Z$-styryl enaminones. The chemoselective addition of $N$-heterocycles 
Table 2. Synthesis of styrylenaminones by the addition of $N$-heterocycles and alkynones. ${ }^{\text {a }}$

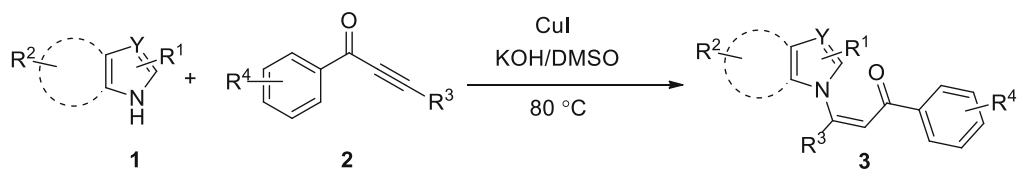

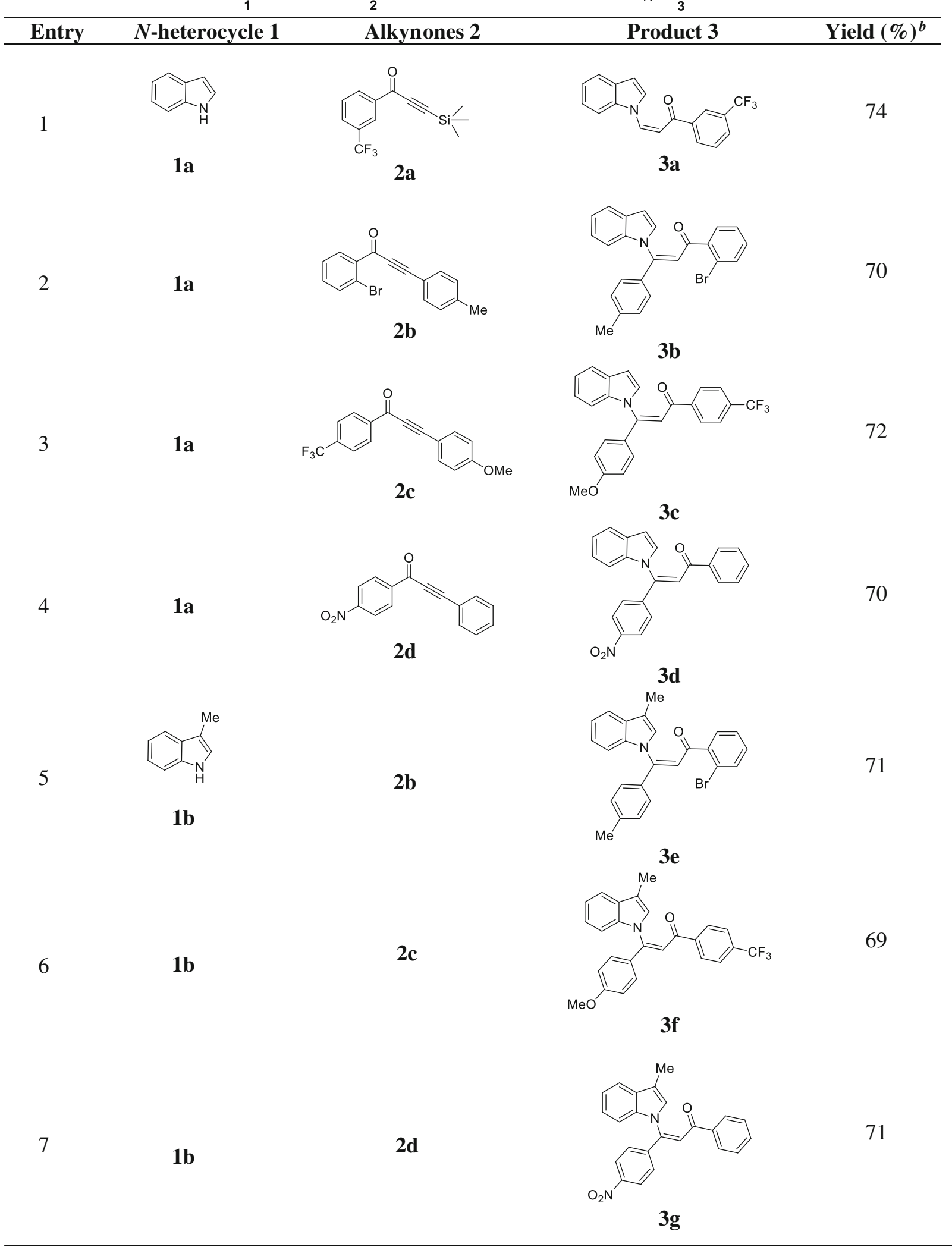


Table 2. (contd.)

8<smiles>NCCc1c[nH]c2ccccc12</smiles>

9

10

1c<smiles></smiles>

1d

12

1d

13

14

15 2a

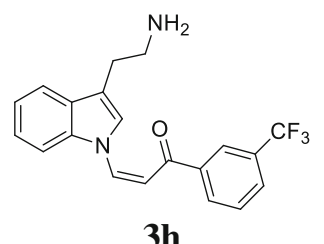

3h

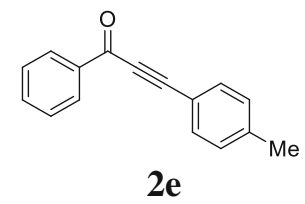

2d

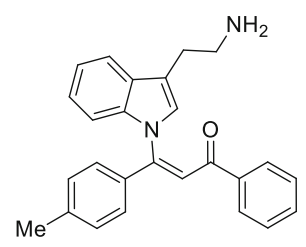

$3 \mathbf{i}$
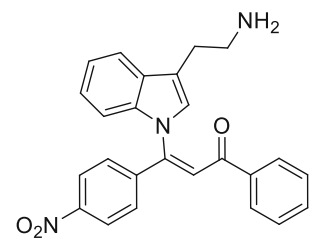

3j

2a

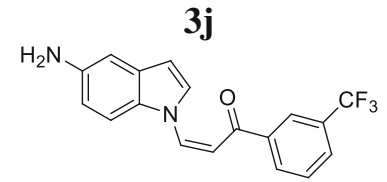

69

69

2b

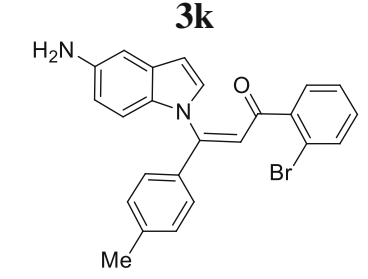

31

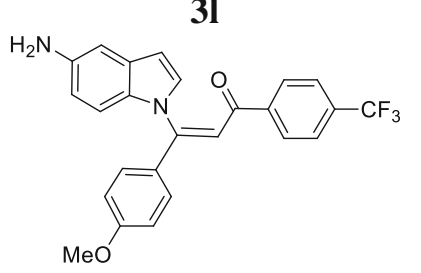

67

69

65

68

61

(1)
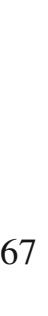

1d

1d

$2 \mathrm{c}$

$2 \mathrm{e}$

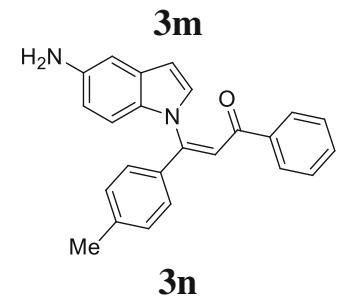

2d

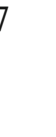


Table 2. (contd.)

16<smiles></smiles>

1e

17

$1 \mathrm{e}$

18<smiles>Brc1ccc2[nH]ccc2c1</smiles>

1f

19<smiles></smiles>

20<smiles>CCc1nc([N+](=O)[O-])c[nH]1</smiles>

1h 2b

$$
\mathrm{MeO}
$$<smiles>O=C(/C=C(/c1ccc([N+](=O)[O-])cc1)n1ccc2ccccc21)c1ccccc1Br</smiles>

$3 p$<smiles>COc1ccc(C(=CC(=O)c2ccccc2)n2ccc3cc(OC)ccc32)cc1</smiles>

$3 q$<smiles>O=C(/C=C(/c1ccc([N+](=O)[O-])cc1)n1ccc2cc(Br)ccc21)c1ccccc1</smiles>

$3 r$<smiles>COc1ccc(C(=CC(=O)c2ccccc2Br)n2ccnc2)cc1</smiles>

$\mathrm{Me}$<smiles></smiles>

Me $3 t$

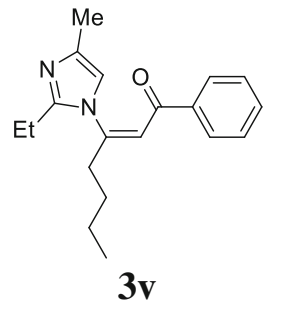

${ }^{\text {a }}$ The reactions were performed using $N$-heterocycle $1(0.5 \mathrm{mmol})$, alkyne $2(0.3 \mathrm{mmol}), \mathrm{CuI}(2 \mathrm{~mol} \%)$ and $\mathrm{KOH}$ (0.2 equiv.) as base in $2.0 \mathrm{~mL}$ of DMSO at $80^{\circ} \mathrm{C}$ for 15 min under nitrogen atmosphere. ${ }^{\text {b }}$ Yield of isolated product. ${ }^{\mathrm{c}}$ Inseparable complex mixture. 


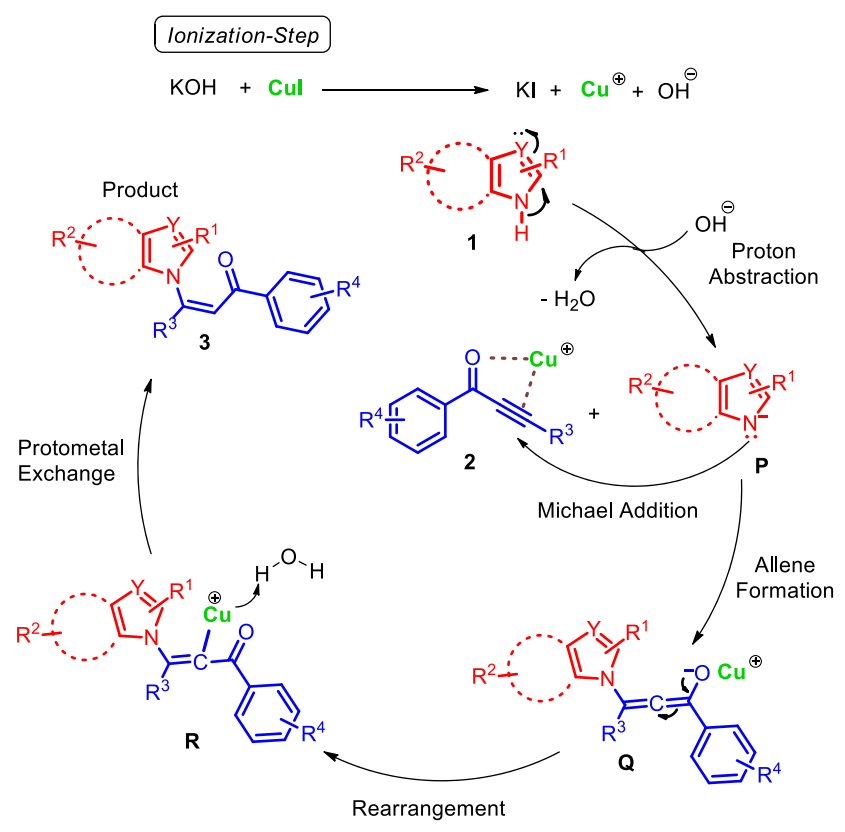

Scheme 2. Probable mechanism via Michael addition.

onto alkynones proceeds without affecting $1^{\circ}$ amino groups (aromatic and aliphatic) present in the substrate and provides a synthetically useful handle in the products for further elaboration. The method involves a facile route, utilizing simple and easily accessible starting materials under non-toxic environment increases the synthetic utility of the developed protocol.

\section{Supplementary Information (SI)}

Characterization data and copies of ${ }^{1} \mathrm{H},{ }^{13} \mathrm{C}$ NMR and HRMS spectra for selected compounds are reported, which available free of charge at www.ias.ac.in/chemsci.

\section{Acknowledgements}

We gratefully acknowledge the Council of Scientific and Industrial Research, India [02(0264)/16/EMR-II] for financial support and USIC, University of Delhi for providing instrumentation facilities. M.P. and Sushmita are thankful to DST-SERB and UGC, New Delhi for fellowships.

\section{References}

1. (a) Jioui I, Danoun K, Solhy A, Jouiad M, Zahouily M, Essaid B, Len C and Fihri A 2016 Modified fluorapatite as a highly efficient catalyst for the synthesis of chalcones via Claisen-Schmidt condensation reaction J. Indus. Eng. Chem. 39 218; (b) Li Z, Zhao H, Han H, Liu Y, Song J, Guo W, Chu W and Sun Z 2017 Graphene-supported $\mathrm{ZnO}$ nanoparticles: An efficient heterogeneous catalyst for the Claisen-Schmidt condensation reaction without additional base Tetrahedron Lett. 58 3984; (c) Sida A, Lamaraa K, Mokhtaria
M, Ziania N and Mosset P 2011 Synthesis and characterization of 1-formyl-3-phenyl-5-aryl-2-pyrazolines Eur. J. Chem. 2 311; (d) Nasr-Esfahani M, Daghaghale M and Taei M 2017 Catalytic synthesis of chalcones and pyrazolines using nanorod vanadate sulfuric acid: An efficient and reusable catalyst J. Chin. Chem. Soc. 6417

2. (a) Gayon E, Szymczyk M, Gerard H, Vrancken E and Campagne J M 2012 Stereoselective and catalytic access to $\beta$-enaminones: an entry to pyrimidines J. Org. Chem. 77 9205; (b) Palmieri G and Cimarelli C 2006 Chemoand stereoselective reduction of enaminones for the preparation of biologically active compounds ARKIVOC vi 104

3. (a) Stompor $\mathrm{M}$, Kałużny $\mathrm{M}$ and $\dot{Z}$ arowska $\mathrm{B}$ 2016 Biotechnological methods for chalcone reduction using whole cells of Lactobacillus, Rhodococcus and Rhodotorula strains as a way to produce new derivatives Appl. Microbiol. Biotechnol. 100 8371; (b) Ritter M, Martins R M, Rosa S A, Malavolta J L, Lund R G, Flores A F C and Pereira C M P 2015 Green synthesis of chalcones and microbiological evaluation J. Braz. Chem. Soc. 26 1201; (c) Valdameri G, Gauthier C, Terreux R, Kachadourian R, Day B J, Winnischofer S M B, Rocha M E M, Frachet V, Ronot X, Pietro A D and Boumendjel A 2012 Investigation of chalcones as selective inhibitors of the breast cancer resistance protein: critical role of methoxylation in both inhibition potency and cytotoxicity J. Med. Chem. 553193

4. (a) Lefemine D V, Damn M and Baratschi F 1962 Isolation and characterization mitiromycin and other antibiotics J. Am. Chem. Soc. 84 3184; (b) Collinus J F 1965 Application of chalcone in synthesis of 1-(1, 5-benzodiazepino) substituted analogues of indole Brit. Med. Bull. 21 223; (c) Schach V W M and Els H 1961 Intramolecular cyclization of unsaturated diazoketones J. Am. Chem. Soc. 83 4678; (d) Garattini S and Valzelli L 1965 Serotonin (Amsterdam: Elsevier) p. 277

5. (a) Karpov A S and Muller T J J 2003 New entry to a three-component pyrimidine synthesis by TMSynones via Sonogashira coupling Org. Lett. 5 3451; (b) Karpov A S and Muller T J J 2003 Straightforward novel one-pot enaminone and pyrimidine syntheses by coupling-addition-cyclocondensation sequences Synthesis $\mathbf{1 8} 2815$

6. (a) Dixon K and Greenhill J V 1974 A study of the rates of hydrolysis of certain enaminones J. Chem. Soc., Perkin Trans. 2 164; (b) Greenhill, J V 1976 Aromatic enaminones. Part 1. Ultraviolet absorption of $N$-aryl enaminones derived from dimedone J. Chem. Soc., Perkin I 2207; (c) Dixon K and Greenhill J V 1976 Use of cyclohexane-1,3-dione derivatives in the preparation of enaminones J. Chem. Soc., Perkin Trans. I 2211

7. (a) Yang Y, Shen Y, Wang X, Zhang Y, Wang D and Shi X 2016 Triazole acetyl gold (III) catalyzed MeyerSchuster rearrangement of propargyl alcohols Tetrahedron Lett. 57 2280; (b) Gandeepan P, Rajamalli P and Cheng C H 2014 palladium-catalyzed dehydrogenative $\beta$-arylation of simple saturated carbonyls by aryl halides ACS Catal. 4 4485; (c) García-Álvarez J, Díez J, Vidal C and Vicent C 2013 New Ag (I)-Iminophosphorane coordination polymers as efficient catalysts precursors for the mw-assisted meyer-schuster rearrangement of 
propargylic alcohols Inorg. Chem. 52 6533; (d) Mattia E, Porta A, Merlini V, Zanoni G and Vidari G 2012 One-pot consecutive reactions based on the synthesis of conjugated enones by the re-catalysed meyer-schuster rearrangement Chem. Eur. J. 1811894

8. (a) Smirnova Y V and Krasnaya Z A 2000 Methods of synthesis of conjugated $\omega$-amino ketones Russ. Chem. Rev. 69 1021; (b) Michael J P, De Koning C B, Gravestock D, Hosken G D, Howard A S, Jungmann C M, Krause R W M, Parsons A S, Pelly S C and Stanbury T V 1999 Enaminones: versatile intermediates for natural product synthesis Pure Appl. Chem. 71 979

9. (a) Lue P and Greenhill J V 1997 Enaminones in heterocyclic synthesis Adv. Heterocycl. Chem. 67 207; (b) Zhang T, Jia Y M, Yan S J, Yu C and Huang Z T 2009 Synthesis of $\mathrm{BF}_{2}$ complex of 3-methylthio enaminones 2009 156; (c) Michael J P and Gravestock D 1997 Enaminones as a intermediate in the synthesis of indolizidines alkaloids Pure Appl. Chem. 69 583; (d) Greenhill J V 1977 Enaminones Chem. Soc. Rev. 6277

10. Jiang H F, Li J H and Chen Z W 2010 One-pot domino reactions for synthesis of heterocyclic[3.3.3]propellanes and spiro[cyclopenta[b]pyridine- $4,2^{\prime}$-indenes] Tetrahedron 669721

11. Chauhan R, Dwivedi J, Anees A A S and Kishore D 2011 Synthesis and antimicrobial activity of chalcone derivatives of indole nucleus Pharma Chem. J. 44542

12. (a) Trofimov B A, Schmidt E Y, Zorina N V, Ivanova E V and Ushakov I A 2012 Transition-metal-free superbasepromoted stereoselective $\alpha$-vinylation of ketones with arylacetylenes: a general strategy for synthesis of $\beta, \gamma$ unsaturated ketones J. Org. Chem. 77 6880; (b) Trofimov
B A, Schmidt E Y, Ushakov I A, Zorina N V, Skitaltseva E V, Protsuk N I and Mikhaleva A I 2010 Base-catalyzed stereoselective vinylation of ketones with arylacetylenes: a new $\mathrm{c}\left(\mathrm{sp}^{3}\right)-\mathrm{c}\left(\mathrm{sp}^{2}\right)$ bond-forming reaction Chem. Eur. J. 168516

13. (a) Patel M, Saunthwal R K and Verma A K 2017 Basemediated hydroamination of alkynes Acc. Chem. Res. 50 240; (b) Verma A K, Joshi M and Singh V P 2011 base-mediated regio- and stereoselective intermolecular addition of alkynes to $N$-heterocycles Org. Lett. 13 1630; (c) Patel M, Saunthwal R K, Dhaked D K, Bharatam P V and Verma A K 2016 Metal-free intermolecular hydrophenoxylation of aryl alkynes Asian J. Org. Chem. 5 213; (d) Joshi M, Patel M, Tiwari R and Verma A K 2012 Base-mediated selective synthesis of diversely substituted $N$-heterocyclic enamines and enaminones by the hydroamination of alkynes J. Org. Chem. 77 5633; (e) Patel M, Saunthawal R K and Verma A K 2014 Base-catalyzed stereoselective intermolecular addition of imidazoles onto alkynes: an easy access to imidazolyl enamines Tetrahedron Lett. 55 1310; (f) Verma A K, Patel M, Joshi M, Likhar P R, Tiwari R K and Parang K 2014 Base-mediated chemo and stereoselective addition of 5-aminoindole/tryptamine and histamines onto alkynes J. Org. Chem. 79172

14. (a) Joshi M, Tiwari R and Verma A K 2012 regioselective preferential nucleophilic addition of $n$-heterocycles onto haloarylalkynes over $N$-arylation of aryl halides Org. Lett. 14 1106; (b) Verma A K, Kesharwani T, Singh J, Tandon V and Larock R C 2009 Regioselective preferential nucleophilic addition of $N$-heterocycles onto haloarylalkynes over $N$-arylation of aryl halides Angew. Chem. Int. Edit. 481138 